\title{
Electrically Switched Cesium Ion Exchange
}

\section{Target Performance Applications and Progress (Milestone \#A1 for Project RL3-6-C3-21)}

Michael A. Lilga

Rick J. Orth

Johanes P. H. Sukamto

Daniel T. Schwartz ${ }^{(a)}$

Scott M. Haight ${ }^{(a)}$

J. David Genders ${ }^{(b)}$

PEe

MAY 271937

OSTI

April 1997

Prepared for the U.S. Department of Energy

Office of Science and Technology within the Office of Environmental Management, Efficient Separations and Processing

Crosscutting Program, under Contract DE-AC06-76RLO 1830

Pacific Northwest National Laboratory

Richland, Washington 99352

(a) University of Washington.

(b) Electrosynthesis Company, Inc. 


\title{
DISCLAIMER
}

This report was prepared as an account of work sponsored by an agency of the United States Government. Neither the United States Government nor any agency thereof, nor Battelle Memorial Institute, nor any of their employees, makes any warranty, expressed or implied, or assumes any legal liability or responsibility for the accuracy, completeness, or usefulness of any information, apparatus, product, or process disclosed, or represents that its use would not infringe privately owned rights. Reference herein to any specific commercial product, process, or service by trade name, trademark, manufacturer, or otherwise does not necessarily constitute or imply its endorsement, recommendation, or favoring by the United States Government or any agency thereof, or Battelle Memorial Institute. The views and opinions of authors expressed

herein do not necessarily state or reflect those of the United States Government or any agency thereof.

\author{
PACIFIC NORTHWEST NATIONAL LABORATORY \\ operated by \\ BATTELLE \\ for the \\ UNITED STATES DEPARTMENT OF ENERGY \\ under Contract DE-AC06-76RLO 1830
}




\section{DISCLAMMER}

Portions of this document may be illegible in electronic image products. Images are produced from the best available original document. 



\section{Summary}

Electrically Switched Ion Exchange (ESIX) is a separation technology being developed at Pacific Northwest National Laboratory (PNNL) as an alternative to conventional ion exchange for removing radionuclides from high-level waste. In conventional ion exchange, secondary wastes are generated with each step needed to complete the removal process (acid elution, exchanger water rinse, and sodium loading of the exchanger). Other disadvantages include a high sodium content of the waste, which affects the waste form for disposal, and frequent replacement of exchangers. The ESIX technology, which combines ion exchange and electrochemistry, is geared toward producing electroactive films that are highly selective, regenerable, and long lasting. During the process, ion uptake and elution are controlled directly by modulating the potential of an ion exchange film that has been electrochemically deposited onto a high surface area electrode. This method adds little sodium to the waste stream and minimizes the secondary wastes associated with traditional ion exchange techniques.

Development of the ESIX process is well underway for cesium removal using ferrocyanides as the electroactive films. Films having selectivity for perrhenate (a pertechnetate surrogate) over nitrate also have been deposited and tested at PNNL. Based on the ferrocyanide film capacity, stability, rate of uptake, and selectivity shown during performance testing, it appears possible to retain a consistent rate of removal and elute cesium into the same elution solution over several load/unload cycles. In batch experiments, metal hexacyanoferrates have shown high selectivities for cesium in concentrated sodium solutions. In these experiments, cesium uptake was unaffected by $\mathrm{Na} / \mathrm{Cs}$ molar ratios of up to $2 \times 10^{4}$, and reached equilibrium within 18 hours. During engineering design tests using 60 pores per inch, high surface area nickel electrodes, nickel ferrocyanide films displayed continued durability, losing less than $20 \%$ of their capacity after $1500 \mathrm{load} /$ unload cycles. Bench-scale flow system studies showed no change in capacity or performance of the films at a flow rate up to $113 \mathrm{BV} / \mathrm{h}$, the maximum flow rate tested, and breakthrough curves further supported once-through waste processing with ESIX.

A case study for the KE Basin on the Hanford Site was conducted based on the results of the development testing. Engineering design baseline parameters for film deposition, film regeneration, cesium loading, and cesium elution were used for developing a conceptual system. Order of magnitude cost estimates were developed to compare with conventional ion exchange. This case study demonstrated that $\mathrm{KE}$ Basin wastewater could be processed continuously with minimal secondary waste and reduced associated disposal costs, as well as lower capital and labor expenditures.

Future work planned for the ESIX technology in FY 1997 includes further optimization of the process with waste simulants. Demonstrating the process with actual wastes will depend on funding availability in FY 1998. 


\section{Acknowledgments}

This work was funded by the Office of Science and Technology, within the U.S. Department of Energy's Office of Environmental Management, under the Efficient. Separations and Processing Crosscutting Program. 
. 


\section{Contents}

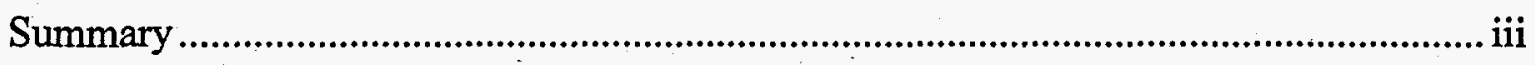

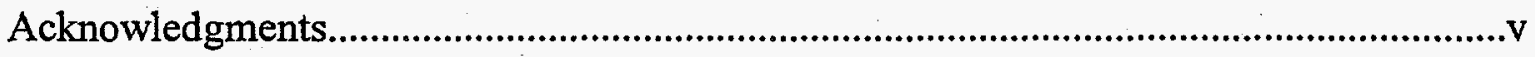

Introduction

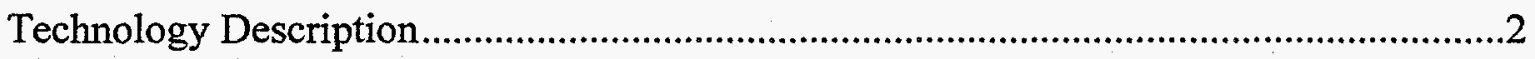



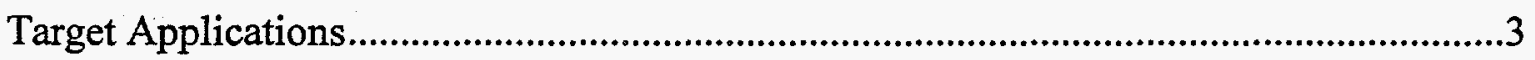

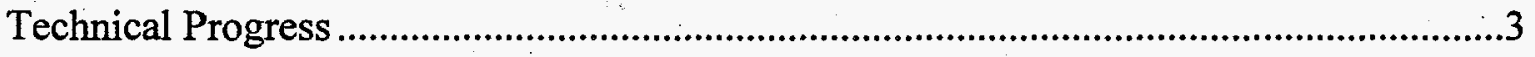

ESIX Case Study for KE Basin Application.................................................................6

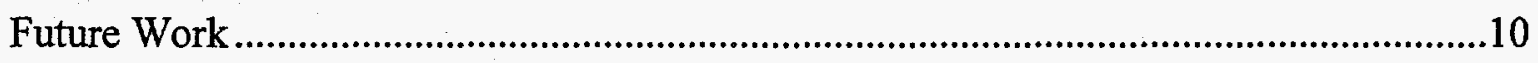

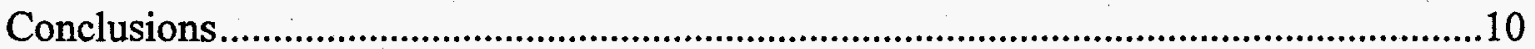

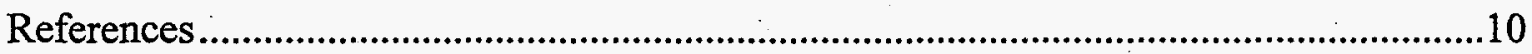




\section{Figures}

1 The ESIX Concept for Cesium Ion Loading and Unloading ...................................2

2 Effect of Flow Rate on Cesium Breakthrough in Flow-through Mode .....................5

3 Effect of $[\mathrm{Cs}]_{0}$ on Cesium Breakthrough in Flow-through Mode...............................5

4 Model Fit to Breakthrough Data for $[\mathrm{Cs}]_{0}=0.18 \mathrm{ppm}$ and Flow Rate $=$ $13 \mathrm{BV} / \mathrm{h}$ in Flow-through Mode ...................................................................6

5 Predicted Breakthrough for ESIX Treatment of KE Basin Water at

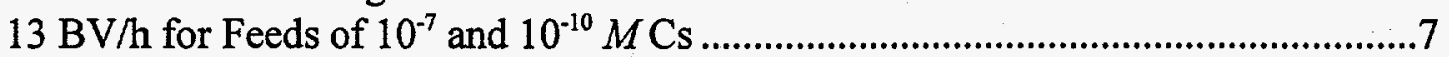

6 Flow Diagram for Waste Decontamination with ESIX ....................................8

7 Conceptual Schematic Electrode Arrangement for KE Basin

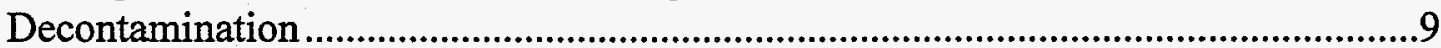




\section{Introduction}

A variety of radioactive wastes are found throughout the U.S. Department of Energy (DOE) complex. These wastes take on many forms, including reactor cooling basin water; underground storage tanks containing high-level radioactive waste (HLW); and groundwater. Along with safety and regulatory requirements for the final waste form, economic considerations, such as the high cost of vitrifying HLW, compel the removal of radionuclides before the procedures for permanent disposal can be carried out. Separating out and concentrating most of the radionuclides would allow the bulk of the waste to be disposed of less expensively as low-level waste (LLW).

The needed separations are not easy; some of the challenges are illustrated by the

${ }^{137} \mathrm{Cs}$ separations that are required. Based on the concentration of ${ }^{137} \mathrm{Cs}$ in tank waste (about $10^{-4} M$ ) and the needed level of decontamination, the separation process must have a decontamination factor of at least 5500. The separation must also be selective for cesium in the presence of sodium concentrations that can be $10^{5}$ times higher. Radioactive cesium concentrations in spent nuclear fuel storage basins $\left(10^{-10} M\right)$ and groundwater $\left(10^{-13} M\right)$ are much lower than that found in tank waste, but often the concentrations of sodium and potassium are still several orders of magnitude higher than cesium. A method of removing cesium is needed that avoids transuranic (TRU) loading of the waste form and does not generate large quantities of secondary waste.

The most accepted option for cesium separation before final disposal is conventional ion exchange. Both inorganic and organic ion exchangers are under consideration. Unfortunately, for regenerable ion exchange materials, a large amount of secondary waste results from the numerous process steps required (acid elution, exchanger water rinse, and sodium loading of the exchanger). Neutralization of the acidic eluant typically adds sodium to the waste, restricting the choice of waste form and limiting the amount of waste that can be incorporated. In addition, it has been reported that organic exchangers lose approximately $3 \%$ of their capacity per cycle (Kurath et al. 1994). Therefore, typical organic exchangers can be used for only 20 to 30 cycles before they must also be disposed of as another form of secondary waste. Most inorganic ion exchange materials are not regenerable, adding substantial costs for ion exchange replacement and secondary waste disposal. The technology discussed in this report is being developed to provide a more economical remediation alternative.

Electrically Switched Ion Exchange (ESIX), being developed at Pacific Northwest National Laboratory (PNNL) ${ }^{(a)}$, combines ion exchange and electrochemistry to provide a selective, reversible method for radionuclide separation that lowers costs typically associated with conventional ion exchange and minimizes secondary waste generation. The ESIX technology is described here, along with progress for specific applications.

(a) Operated by Battelle for the U.S. Department of Energy under Contract DE-AC06-76RLO 1830. 


\section{Technology Description}

In the ESIX process, an electroactive ion exchange film is electrochemically deposited onto a high surface area electrode, and ion uptake and elution are controlled directly by modulating the potential of the film. At PNNL, films for cesium removal have been prepared and tested, and process development and optimization are well underway. More recently, films selective for $\mathrm{ReO}_{4}{ }^{-}$(a pertechnetate surrogate) have been developed. For cesium, the electroactive films being tested are ferrocyanides, which are well known to have high selectivities for cesium in concentrated sodium solutions. When a cathodic potential is applied to the film, $\mathrm{Fe}^{+3}$ is reduced to the $\mathrm{Fe}^{+2}$ state, and a cation must be intercalated into the film to maintain charge neutrality (i.e., $\mathrm{Cs}^{+}$is loaded). Conversely, if an anodic potential is applied, a cation must be released from the film (i.e., $\mathrm{Cs}^{+}$is unloaded). Therefore, to load the film with cesium, the film is simply reduced; to unload cesium, the film is oxidized. Figure 1 illustrates the concept for cesium. In $\mathrm{ReO}_{4}{ }^{-}$ (i.e., $\mathrm{TcO}_{4}{ }^{-}$) separation (which uses a different proprietary film), loading occurs when the film is oxidized and unloading occurs upon film reduction.
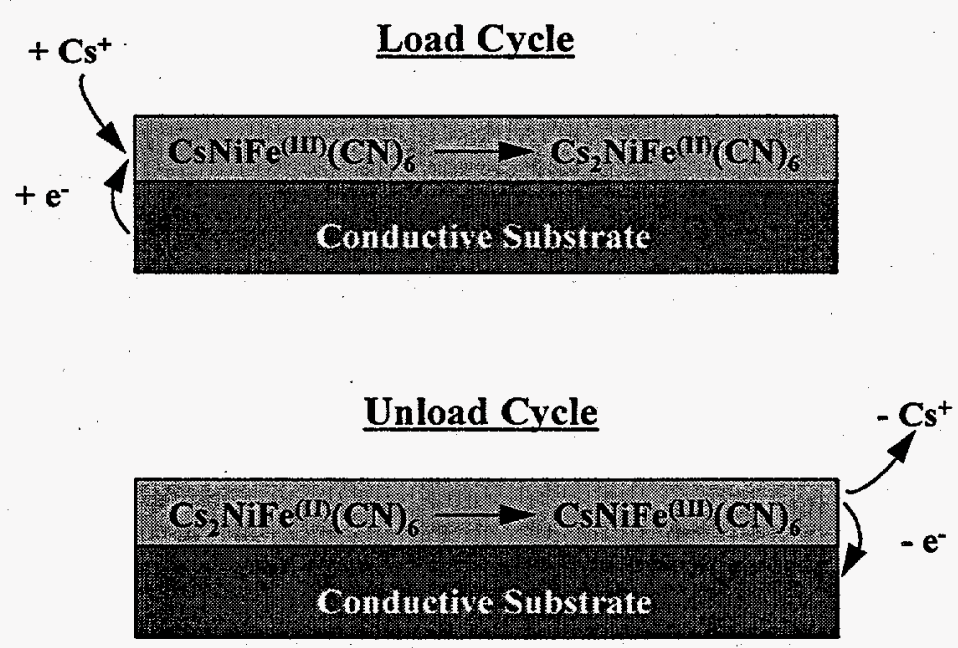

Figure 1. The ESIX Concept for Cesium Ion Loading and Unloading

\section{Advantages of ESIX}

ESIX is a regenerable ion exchange process that has great potential to minimize secondary waste and produce a low-sodium, cesium-rich waste stream. An important advantage of the ESIX process is that it is possible to elute cesium into the same elution solution over several load cycles, because the unload step is conducted electrochemically without added chemicals and is independent of the soluble cesium concentration. This improved process would result in the generation of a waste stream with a very low 
sodium concentration and a cesium concentration that is limited only by solubility, radiation, and heat generation. Such a HLW feed stream allows consideration of a broader range of final waste forms, including those that cannot tolerate sodium. The production of secondary waste would be minimized, since the large volumes of solution associated with elution, wash, and regeneration cycles typical of standard ion exchange are not needed for the ESIX process. A small amount of wash solution may be necessary after the unload cycle, but this solution could be used in subsequent cycles for unloading the exchanger. Ratios of the volume of generated secondary waste to the volume of processed waste are estimated to be as low as 0.0006 for the ESIX process, or about two orders of magnitude lower than for a typical regenerable process using CS-100 ion exchange resin.

\section{Target Applications}

Based on current ESIX process knowledge, the most likely applications of this technology for cesium separations are for waste streams with a pH less than about 11 . Target wastes include basin water (KE Basin, KW Basin, and N Basin at the Hanford Site; Savannah River Site basins), groundwater (TAN TSF-05 Injection Well at the Idaho Site), and acidic tank wastes (Idaho Site). This technology could also find application for treatment of wastewater generated during decontamination and decommissioning operations and other waste processing activities across the DOE complex.

The recent development of films selective for $\mathrm{ReO}_{4}^{-}, \mathrm{a} \mathrm{TcO}_{4}^{-}$analog, shows promise for application of the ESIX technology to technetium-bearing wastes and groundwater.

\section{Technical Progress}

The objective of this project is to establish the viability of ESIX by increasing the stability and capacity of electroactive films and determining uptake and elution parameters of the process under flow conditions. Work in FY 1996 to develop the ESIX technology for cesium separation focused on deposition of films with higher capacities and stabilities than for previously reported films (Bocarsly and Sinha 1982). The results from the FY 1996 testing were used for expanded testing in FY 1997 that included deposition on high surface area electrodes and bench-scale flow studies. A conceptual process was devised for cesium separation based on a case study of the Hanford KE Basin.

Deposition procedures were developed in FY 1996 (Lilga et al. 1996) using nickel ferrocyanide films, $\mathrm{M}_{2} \mathrm{NiFe}(\mathrm{CN})_{6}(\mathrm{M}=\mathrm{Na}, \mathrm{K})$. These films are prepared by electrochemically oxidizing a nickel electrode in a $\mathrm{Fe}(\mathrm{CN})_{6}^{-3}$ solution, precipitating the active film on the electrode surface. Electrochemical deposition gives reproducible films 
with reversible behavior; i.e., metal ions are loaded and unloaded reversibly by switching the electrode potential. Films prepared by modified literature procedures (named PNNL1 and -2) have higher capacity and stability than those previously reported in the literature, while retaining the high selectivity for cesium that ferrocyanide materials are known to possess.

Films prepared to date on flat-plate electrodes using PNNL procedures have almost twice the capacity of previously reported films and lose less than $20 \%$ of their capacity after 2000 load/unload cycles. In contrast, a literature film on a flat plate lost $50 \%$ of its capacity after the same cycling. In studies during FY 1997, films on 60 pores per inch (ppi) $\left(40 \mathrm{~cm}^{2} / \mathrm{cm}^{3}\right)$ high surface area nickel foam electrodes lost about $20 \%$ of their capacity after $1500 \mathrm{load} /$ unload cycles. Flow cell experiments (discussed in more detail below) show that films on 60 ppi electrodes are stable under flow conditions; the maximum flow rate tested to date is 113 bed volumes per hour $(\mathrm{BV} / \mathrm{h})$.

The use of metal hexacyanoferrates, which are known cesium ion exchange materials (Lehto and Harjula 1987), gives high selectivity for cesium over sodium as shown by cyclic voltammetry (Lilga et al. 1996) and in batch experiments. In the batch experiments, cesium uptake was unaffected by $\mathrm{Na} / \mathrm{Cs}$ molar ratios of up to $2 \times 10^{4}$. Cesium uptake reached equilibrium within $18 \mathrm{~h}$ in the batch experiments.

Bench-scale flow experiments were conducted in which cesium uptake was measured as a function of flow rate and initial cesium concentration, $[\mathrm{Cs}]_{0}$, for solutions passed through a 60 ppi nickel foam electrode upon which the electroactive film was deposited using the PNNL-2 method. Experiments reported here were conducted without applying a potential and in flow-through mode, in which solution was forced through the $2.8 \mathrm{~cm} \times 2.1 \mathrm{~cm}$ face of the high surface area electrode, passing through the electrode thickness of $0.64 \mathrm{~cm}$ ("length/diameter", or $1 / \mathrm{d}=0.3$ ). Figure 2 shows breakthrough curves for a feed containing $0.2 \mathrm{ppm} C s$ as a function of flow rate. In nonradioactive testing, $0.2 \mathrm{ppm}$ Cs was the lowest concentration that could be used due to cesium detection limits of approximately $0.02 \mathrm{ppm}$ for atomic absorption analyses. At $13 \mathrm{BV} / \mathrm{h}$, no breakthrough was observed until about $22 \mathrm{BV} ; 50 \%$ breakthrough occurred at $50 \mathrm{BV}$. Similar behavior was observed at slower flow rates, but breakthrough occurred immediately at the faster flow rates tested.

The breakthrough curves were well defined, even though the $1 / \mathrm{d}$ for the flowthrough set-up was relatively low. The low $1 / \mathrm{d}$ does not allow for fully developed flow, and there is significant dispersion. With a higher $1 / \mathrm{d}$, much sharper breakthrough curves should be obtained.

Initial cesium concentration did not greatly affect breakthrough for $[\mathrm{Cs}]_{0}$ of 0.12 and $0.18 \mathrm{ppm}$ at a flow rate of $8 \mathrm{BV} / \mathrm{h}$ (Figure 3 ). Breakthrough occurred rapidly at a feed concentration of $0.38 \mathrm{ppm}$. 


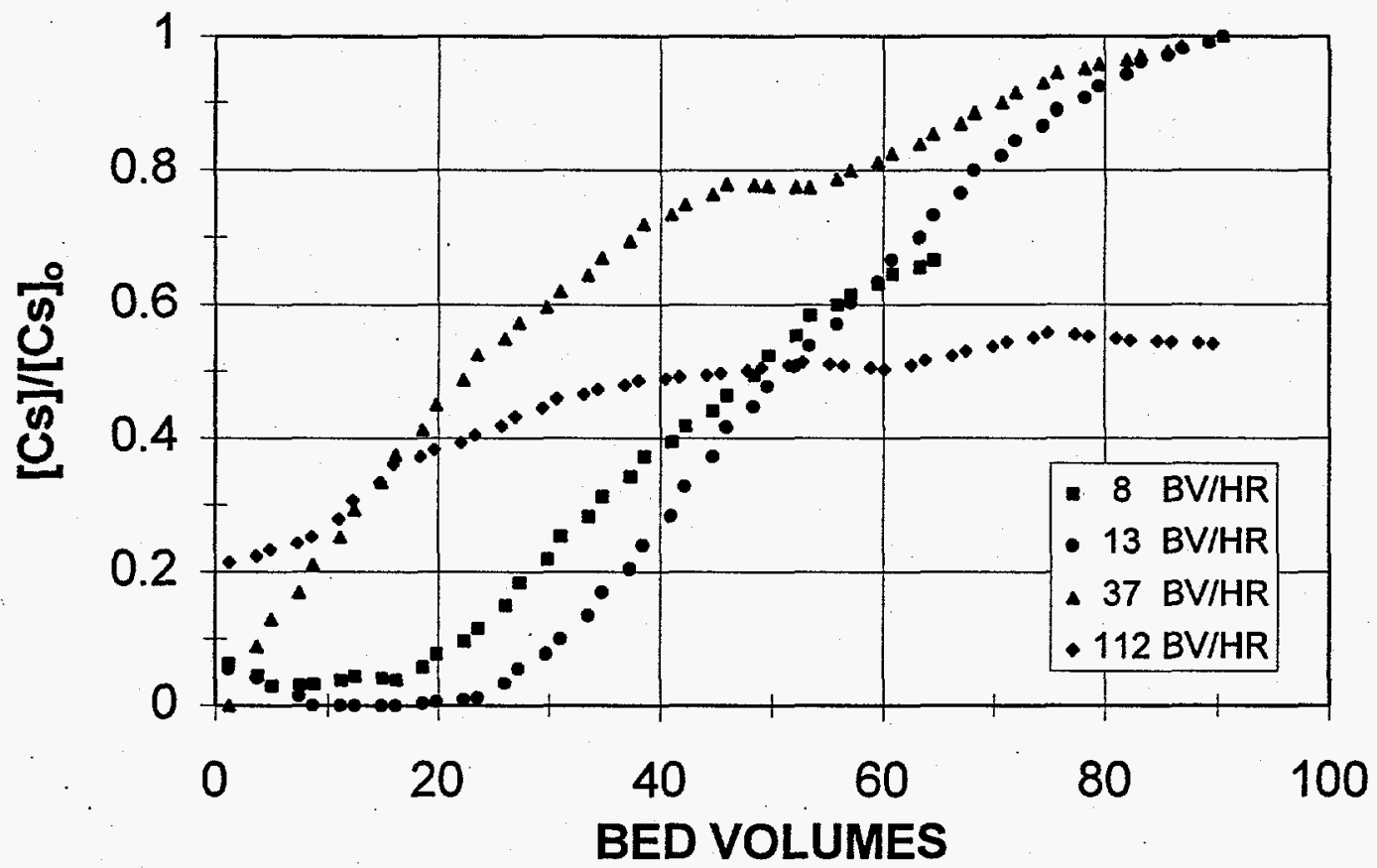

Figure 2. Effect of Flow Rate on Cesium Breakthrough in Flow-through Mode $\left([\mathrm{Cs}]_{0}=0.2 \mathrm{ppm}\right)$



Figure 3. Effect of $[\mathrm{Cs}]_{0}$ on Cesium Breakthrough in Flow-through Mode (flow rate $=8 \mathrm{BV} / \mathrm{h}$ ) 
The flow studies show that films are stable up to the maximum flow rate tested of $113 \mathrm{BV} / \mathrm{h}$. No systematic decline in capacity or performance was observed throughout experimentation. Also, a different electrode with a fresh film gave the same results, indicating consistency from one film deposition to the next.

\section{ESIX Case Study for KE Basin Application}

Results are presented here for a case study for cesium removal from $\mathrm{KE}$ Basin. The case study shows considerable savings in capital expenditures, as well as decreased costs for secondary waste disposal. While estimates are based on $\mathrm{KE}$ Basin, results are expected to also be comparable to the cost savings and reduced secondary waste volumes attainable for the other waste feeds listed in the Target Applications section, where conventional ion exchange is used to remove the cesium.

\section{Bases and Assumptions}

Experimental data were used to predict the breakthrough characteristics for $\mathrm{KE}$ Basin feeds. A model was used to fit breakthrough data obtained during the bench-scale flow testing at $13 \mathrm{BV} / \mathrm{h}$ and $0.18 \mathrm{ppm} \mathrm{Cs}$ (Figure 4). Model parameters were then applied to the range of concentrations of cesium encountered in KE Basin $\left(10^{-7} M\right.$ near the bottom, $10^{-10} \mathrm{M}$ near the top), assuming the same flow rate would be used in the scaled-up system. Figure 5 shows the predicted column performance; $50 \%$ breakthrough is expected to occur after 1,000 to $1,000,000 \mathrm{BV}$ for the highest and lowest concentrations, respectively.

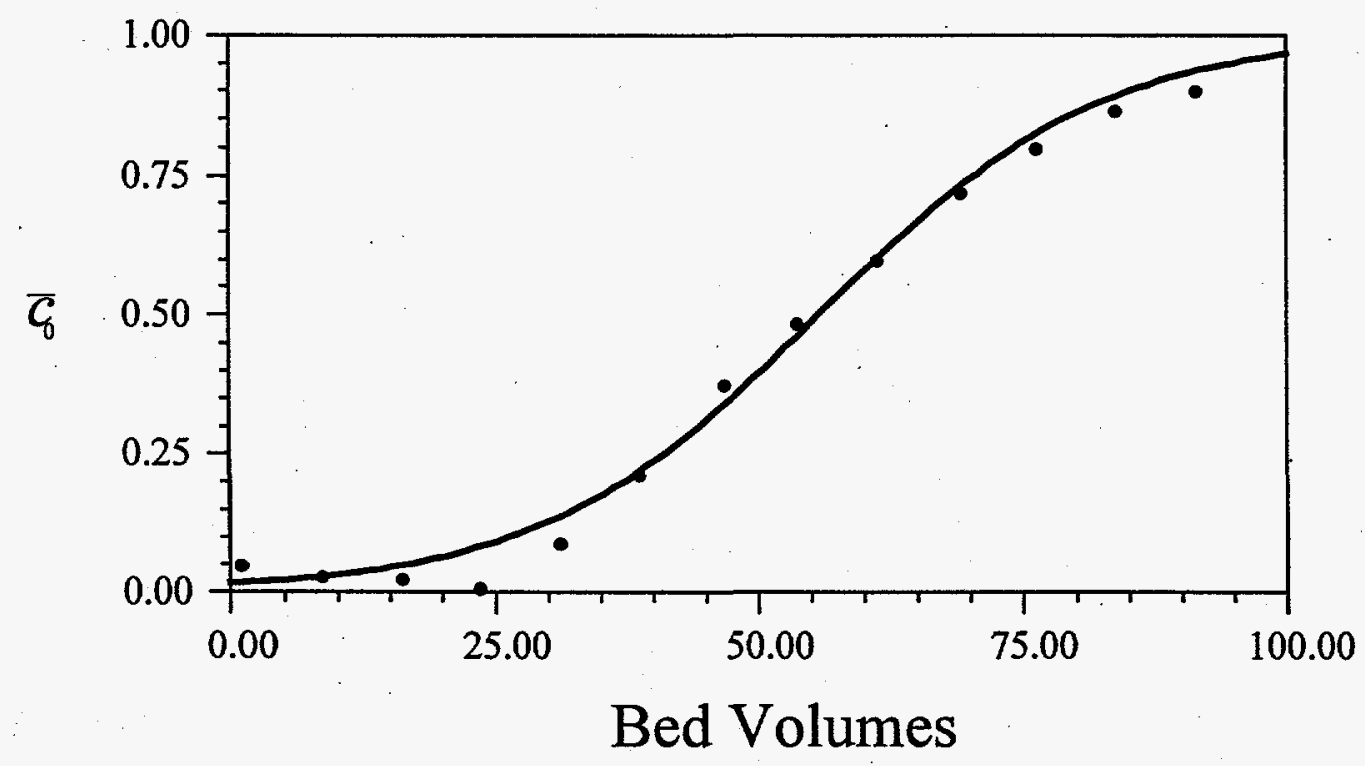

Figure 4. Model Fit to Breakthrough Data for $[\mathrm{Cs}]_{0}=0.18 \mathrm{ppm}$ and Flow Rate $=$ $13 \mathrm{BV} / \mathrm{h}$ in Flow-through Mode 


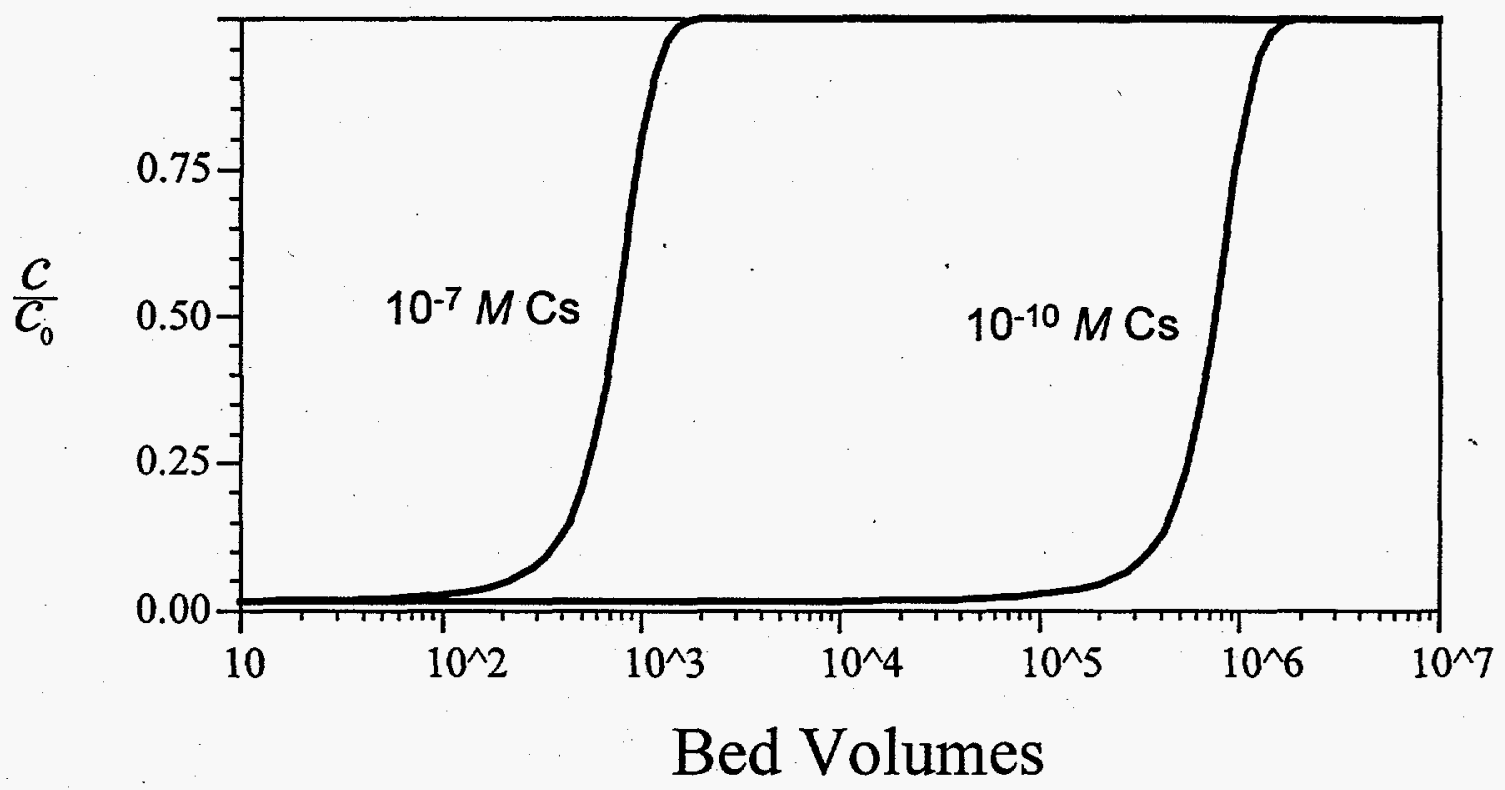

Figure 5. Predicted Breakthrough for ESIX Treatment of KE Basin Water at $13 \mathrm{BV} / \mathrm{h}$ for Feeds of $10^{-7}$ and $10^{-10} \mathrm{M} \mathrm{Cs}$

The modeling results were combined with conservative (worst-case) design baseline parameters for film deposition, film regeneration, cesium loading, and cesium elution, most of which were based on experimental results. Some of the engineering bases were that the electroactive film would be deposited after every 2000 load/unload cycles; film regeneration would take 10 minutes (or less) with an applied potential of 0.1 $\mathrm{V}$ (SCE); the nominal film capacity is $1.7 \times 10^{-9} \mathrm{moles} \mathrm{Cs} / \mathrm{cm}^{2}$ electrode surface area; loading would be carried out by ion exchange without application of a potential; elution would take 10 minutes at an applied potential of $0.8 \mathrm{~V}$; the average concentration of the waste stream is $1 \times 10^{-9} \mathrm{MCs}$ (slightly higher than the cesium concentration currently being processed); a flow rate of $400 \mathrm{dm}^{3} / \mathrm{min}$ is needed; cesium would be eluted just before the predicted initial breakthrough rather than $50 \%$ breakthrough, and, 2 bed volumes of rinse solution would be required after each elution.

For the KE Basin processing, the ESIX system would be used in semi-continuous batch recycle mode, as shown in Figure 6. This same mode of operation is currently conducted via conventional ion exchange to minimize worker exposure to cesium by maintaining a low "steady state" cesium concentration in the Basin. Basin water (or other feed) would be passed through the ESIX column until capacity was reached. The system could also be used in single-pass operation for final water decontamination or in applications in which batch recycle is not desired or feasible. When the column has reached capacity, the feed to the system is stopped. Cesium is then eluted into an elution solution, which is pumped through the system from a holding tank. The elution solution can be reused several times until a limiting (i.e., heat load, radiation constraints, etc.) final cesium concentration is reached. 

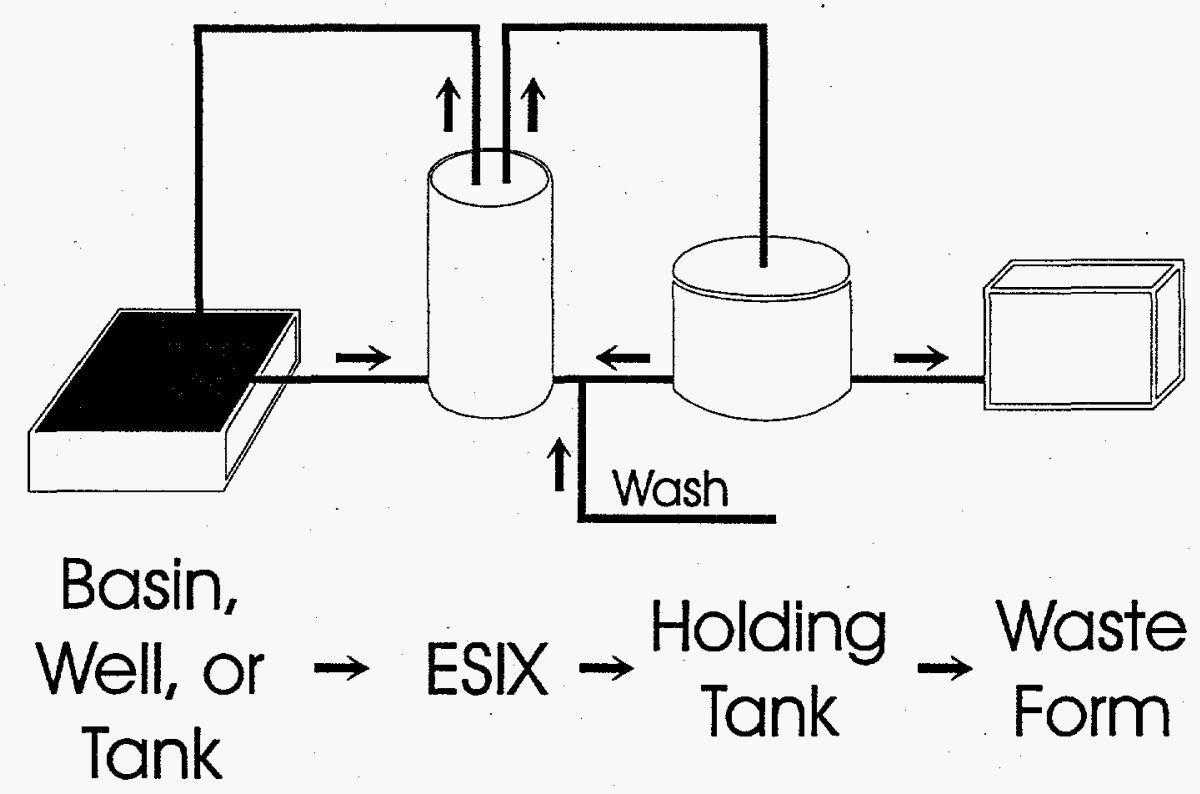

Figure 6. Flow Diagram for Waste Decontamination with ESIX

For this analysis, it was assumed that the elution solution would be disposed of after 10 elution cycles; however, more could possibly be accommodated, depending on the desired composition of the final waste cesium product. A wash solution, needed to remove residual cesium for improved process efficiency, could be added to the holding tank after each wash. Alternately, the wash solution could be kept separate, reused until a threshold concentration is reached, and used later as the next elution solution. The elution solution is periodically transferred from the holding tank to the final waste form.

\section{Process Concept and Estimated Costs}

The ESIX system conceptually would consist of 40 production modules. Each production module would contain 20 ESIX electrodes ( 60 ppi nickel foam) with an associated mesh counter electrode. Production modules could be arranged in two parallel series of 20 each as shown in Figure 7. The electrode volume in each production module would be approximately $0.05 \mathrm{~m}^{3}$, and the surface area would be $200 \mathrm{~m}^{2}$. The total ESIX system working electrode volume would be approximately $2 \mathrm{~m}^{3}$.

Given the above bases and flow diagram, 20,000 BV of waste would be processed before elution of the ESIX system is required. This corresponds to approximately $40 \times 10^{6}$ liters of waste processed and 70 days processing time for each load cycle. Over 7 years continuous operation (assumed K-Basin baseline), approximately 40 load/elution cycles would be required; thus, film redeposition would not be required.

An "order of magnitude" capital cost of $\$ 2 \mathrm{M}$ is estimated for the 40 production modules. Each production module (containing the 20 ESIX electrodes and mesh counter 


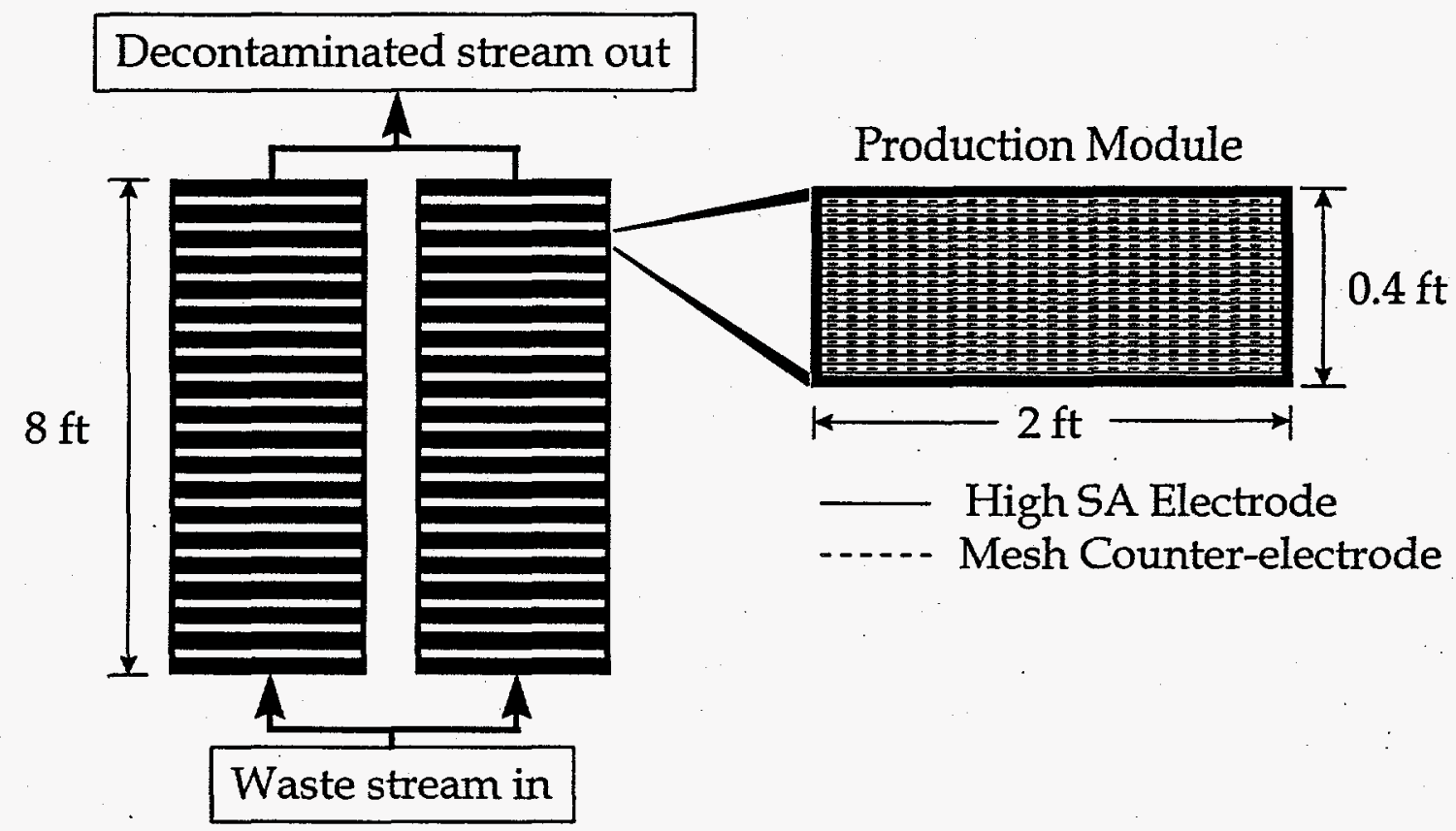

Figure 7. Conceptual Schematic Electrode Arrangement for KE Basin Decontamination

electrodes) would cost on the order of $\$ 50,000$ each. This estimate only includes the production modules and electrodes, which are anticipated to be the major equipment costs associated with the system. Costs associated with radiological applications are not included in this estimate.

\section{Potential Advantages of ESIX for K Basin Application}

The ESIX system could have several significant advantages over current operations. Secondary waste would be reduced at least by a factor of four. Current processing requires disposal of ion exchangers every month. Waste from this source totals approximately $80 \mathrm{~m}^{3}$ with a disposal cost of between $\$ 150 \mathrm{~K}$ and $\$ 300 \mathrm{~K}$ year (assuming disposal costs of $\$ 1,800$ to $\$ 3,600 / \mathrm{m}^{3}$ for LLW). Reusing the elution solution 10 times and assuming a $2 \mathrm{BV}$ rinse volume, the ESIX system is estimated to generate $20 \mathrm{~m}^{3}$ of secondary waste, costing $\$ 38 \mathrm{~K}$ to $\$ 75 \mathrm{~K} /$ year for the same LLW disposal. Costs for ESIX could be lower if the elution solution is used more than 10 times and if the rinse solution is reused as the next elution solution. Monthly replacement costs of exchangers in the current system are estimated to be $\$ 1.2 \mathrm{M} /$ year. The ESIX system requires a one-time capital outlay of on the order of $\$ 2 \mathrm{M}$, having a payback period of approximately 1-2 years. Labor costs and worker exposure might also be less since the current monthly column changeout is not needed for the ESIX system. Worker exposure could also be lower with ESIX because automated or remote operations are possible. 
Another potential advantage of ESIX is that loading with TRU is not expected to be a problem. Unlike the deep-bed filtration of colloidal TRU, which plagues standard ion exchange columns, TRU is less likely to accumulate on the open pore structure of the ESIX electrodes. If a small amount of TRU hangs up on the ESIX column during loading, it still may not contaminate the cesium product during elution. Elimination of TRU in the final waste allows higher cesium loading and less waste volume.

\section{Future Work}

Future work to continue optimization of the ESIX system will be conducted in FY 1997. Flow testing in a stacked configuration with additional electrodes to increase the $1 / \mathrm{d}$ ratio is planned. Application of a potential during loading will be tested, since this may give a higher loading capacity and faster kinetics. Further work on elution during flow testing is needed and a better determination of the required rinse volumes must be made. Demonstration of the technology on actual wastes would require FY 1998 funding.

\section{Conclusions}

Experimental results support the viability of once-through or batch recycle waste processing with ESIX for cesium removal. Electroactive films on high surface area electrodes are stable to solution flow; have high selectivity for cesium in the presence of at least $2 \times 10^{4}$ molar excess of sodium ion; can be cycled through load/unload cycles up to 1500 times; and have sufficient capacity to support a cesium separation process. From the design baseline parameters derived from current processing knowledge and experimental results, a concept for an economical remediation system has been devised and presented. A case study for continuous processing of $\mathrm{KE}$ Basin wastewater shows the potential for significant reduction of secondary wastes and associated disposal costs, and decreased capital and labor expenditures. Other processing improvements with ESIX include less likelihood of TRU contamination; decreased worker exposure because of less contact with exchangers and process hardware; and production of a cesium product containing a minimal amount of sodium, which would be compatible with a wider variety of final waste forms.

\section{References}

Bocarsly, A. B., and S. Sinha. 1982. "Chemically Derivatized Nickel Surfaces: Synthesis of a New Class of Stable Electrode Interfaces. " Journal of the Electroanalytical Chemistry and Interfacial Electrochemistry 137:157. 
Kurath, D. E., L. A. Bray, K. P. Brooks, G. N. Brown, S. A. Bryan, C. D. Carlson, K. J. Carson, J. R. DesChane, R. J. Elovich, and A. Y. Kim. 1994. Experimental Data and Analysis to Support the Design of an Ion-Exchange Process for the Treatment of Hanford Tank Waste Supernatant Liquids. PNNL-10187, Pacific Northwest National Laboratory, Richland, Washington.

Lehto, J., and R. Harjula. 1987. "Separation of Cesium from Nuclear Waste Solutions with Hexacyanoferrate(II)s and Ammonium Phosphomolybdate." Solvent Extraction and Ion Exchange 5:343.

Lilga, M. A., R. J. Orth, J. P. -H. Sukamto, D. T. Schwartz, S. M. Haight, and D. Genders. 1996. Electrically Switched Cesium Ion Exchange. FY 1996 Annual Report. PNNL-11441, Pacific Northwest National Laboratory, Richland, Washington. 
